\title{
The Biomagnification of Polychlorinated Biphenyls, Toxaphene, and DDT Compounds in a Lake Michigan Offshore Food Web
}

\author{
Marlene S. Evans ${ }^{1}$, George E. Noguchi ${ }^{2}$, and Clifford P. Rice ${ }^{3}$ \\ Center for Great Lakes and Aquatic Sciences, The University of Michigan, Ann Arbor, Michigan 48109, USA
}

\begin{abstract}
The biomagnification of polychlorinated biphenyls (PCB), toxaphene, and the DDT family of metabolites was investigated in the epibenthic Mysis relicta (mysid), the benthic Pontoporeia hoyi (amphipod), plankton, particulate flux, surficial sediments, and Myoxocephalus thompsoni (deepwater sculpin) in southeastern Lake Michigan. DDE was the most strongly biomagnified compound, increasing 28.7 times in average concentration from plankton to fish. PCB increased 12.9 times in average concentration from plankton to fish while toxaphene increased by an average factor of 4.7. Particle flux was comprised of lower chlorinated PCB homologues (average chlorine number $=3.8$ ) than the biota $(4.5-5.0)$ and sediments (4.6), possibly reflecting strong influences from atmospheric deposition and/or zooplankton egestion. The percent of higher chlorinated PCB homologues (5 and 6 chlorine atoms per PCB molecule) increased from $54-56 \%$ of the total PCB in plankton and $M$. relicta, to $61 \%$ in $P$. hoyi, to $74 \%$ in sculpins. Amphipods contained greater concentrations than mysids of PCB, DDT residues, and toxaphene, possibly reflecting differences in habitat (benthic vs epibenthic) and diet (detritus vs plankton). Based on estimates of average areal biomass and contaminant concentration, offshore Lake Michigan $P$. hoyi populations contain approximately 15.0 times as much toxaphene, 9.5 times as much total DDT, and 12.0 times as much PCB as the offshore $M$. relicta populations. Thus, amphipods may represent a greater reservoir than mysids for contaminant storage and subsequent recycling in offshore Lake Michigan.
\end{abstract}

\footnotetext{
1 Present address: National Hydrology Research Institute, 11 Innovation Boulevard, Saskatoon, Saskatchewan, Canada S7N 3H5.

${ }^{2}$ Present address: U.S. Fish and Wildlife Service, National Fisheries Research Center-Great Lakes, Ann Arbor, Michigan 48105, USA.

${ }^{3}$ Present address: Patuxent Wildlife Research Center, Environmental Chemistry, Laurel, Maryland 20708, USA.
}

Certain classes of organic contaminants are highly persistent and continue to be of environmental concern years after production bans have been implemented. Polychlorinated biphenyls (PCB), the DDT (dichloro-diphenyltrichloroethane) family of residues, and toxaphene (a complex mixture of polychlorinated terpenes) are familiar examples of such compounds which are of continuing concern in regions such as the Laurentian Great Lakes (Hallett 1988). These compounds continue to enter the Great Lakes where they are bioconcentrated by the biota and biomagnified through successively higher trophic levels. Contaminants also become associated with sinking particles, eventually reaching the lake floor. Some contaminants may re-enter the water column with resuspension and through food web pathways. Of particular relevance to this paper, is the distribution and potential recycling of $\mathrm{PCB}$, DDT residues, and toxaphene through benthic-based food webs.

This paper presents the results of a study investigating PCB, DDT (and its metabolites), and toxaphene body burdens in the mysid Mysis relicta and the amphipod Pontoporeia hoyi, their potential food, and a major fish predator at a $97-\mathrm{m}$ deep station in eastern Lake Michigan. In addition, data are presented on the average chlorine number of the PCB homologues in these various cosystem compartments. Finally, the relative roles of amphipods and mysids in contaminant biomagnification and recycling were investigated.

\section{Materials and Methods}

\section{Field Methods}

The organic-contaminant study was conducted in 1982 as part of a larger study investigating particle flux dyramics. With the exception of the particle flux samples (see below), all other samples for organic-contaminant analysis were collected in April, June, August, and September 1982. All collections were made at a single, 97-m station located approximately $20 \mathrm{~km}$ offshore of Grand Haven, Michigan. This station has been the site of many ecological investigations (Evans et al. 1982; Evans and Landrum 1989).

Mysids were collected at dusk by towing a $1024 \mu \mathrm{m}$ mesh nes 
vertically through the metalimnion. Mysids were sorted into three size categories; 7-10 mm, $10-14 \mathrm{~mm}$, and $>14 \mathrm{~mm}$. Plankton, representing the mysid diet, was collected by hauling $156-\mu \mathrm{m}$ and $76-\mu \mathrm{m}$ mesh, $50-\mathrm{cm}$ diameter nets vertically through the upper $50 \mathrm{~m}$ of the water column.

Sediment and $P$. hoyi were collected in August and September. A PONAR dredge was used. The surficial layer (upper $2 \mathrm{~cm}$ ) of sediment, representing the amphipod diet, was subsampled. Amphipods were gently sieved from the remaining sediment.

Deepwater sculpins (Myoxocephalus thompsoni) were sampled in June, August, and September. Fish were collected with a semi-balloon, nylon otter trawl equipped with a $4.9 \mathrm{~m}$ headrope and $5.8 \mathrm{~m}$ footrope. The body and codend of the trawl were composed of 1.6cm-bar mesh. All biological (plankton, mysids, amphipods, fish) and surficial-sediment samples were placed in solvent-rinsed mason jars and immediately frozen.

Sediment traps were used to collect particle flux samples at 20 , $30,40,80$, and $95 \mathrm{~m}$ depth for organic contaminant analysis. Traps were $10 \mathrm{~cm}$ in diameter and $50 \mathrm{~cm}$ long. A funnel placed at the bottom of each trap channelled particles into a sampling bottle containing either chloroform or mercuric chloride; the latter were added to retard decomposition: there were no significant differences in contaminant concentration nor composition between mercuric chloride and chloroform-preserved samples. Traps were deployed for one-month intervals between April and October. Samples collected between June and September were combined for each of the five depths to characterize contaminant flux during summer at each of the five depths.

Sediment trap samples were analyzed for two reasons. First, because particle flux is largely composed of detritus and resuspended minerals (Evans, unpublished data), flux samples provide a second estimate (in addition to surficial sediments) of the organic contaminant component of the amphipod diet. Second, particle flux represents the major pathway by which organic contaminants entering the lake surface are transported to the lake floor.

\section{Laboratory Methods}

Except for sculpins, all samples were prepared for extraction by freeze drying. Samples were lyophilized in the side arms of the freeze drier's main lyophilization chamber. The possible loss of the volatile contaminant constituents during freeze drying was investigated by placing two soft polyurethane foam plugs in the sidearm prior to sample freeze drying. Subsequent chemical analysis of the plugs (following sample freeze drying) confirmed that no significant volatilization loss of contaminants had occurred during lyophilization. Moreover, contaminant recoveries averaged greater than $70 \%$ through all of the sample cleanup and subsequent fractionations. Replicate analyses had a relative error of less than $25 \%$.

The resulting lyophilized samples were ground with a mortar and pestle, and extracted for $16 \mathrm{hr}$ in a microsoxhlet apparatus with petroleum ether: sculpins, which were not lyophilized, were homogenized in a blender. A $5 \mathrm{~g}$ subsample (from each sample) was mixed with $20 \mathrm{~g} \mathrm{Na}_{2} \mathrm{SO}_{4}$ and extracted with a hexane-acetone mixture $(50: 50)$ for $24 \mathrm{hr}$ in a Soxhlet apparatus. Coextractable interferences were removed from the extracts by alumina column chromatography (Evans et al. 1982). PCB and pesticides were fractionated by silicic acid (Evans et al. 1982) and were analyzed with a Varian 3700 gas chromatograph equipped with an electron-capture detector. PCB was separated on a $2 \mathrm{~m}$ column packed with $5 \%$ SP-2100 on $100 / 120$ Supelcoport ${ }^{\circledR}$. PCB Aroclors ${ }^{3} 1242$ and 1254 provided the best match with the PCB mixture found in the samples and were used for quantification. Pesticides ( $p, p^{\prime}$-DDT, $p, p^{\prime}$-DDE, $p, p^{\prime}$ DDD, and toxaphene) were resolved with a $50 \mathrm{~m}$ SE-54 capillary column. This instrument was not available when the PCB analyses were conducted. Mass spectrophometric analysis was a standard confirmation procedure employed during the batch run of samples collected during this and related contaminant studies.

Polychlorinated biphenyls were quantified by the method described by Rice and White (1987), a modification of the technique proposed by Webb and McCall (1973) and refined by Sawyer (1978). The Sawyer method for packed-column quantification is based on the application of peak-specific response correction factors and ultimately allows for total PCB homologue characterization. The Rice and White modification improves Sawyer's response correction factors by correcting for peak overlap. Application of these response factor corrections assumes that the relative proportions of PCB homologues are the same as in standard PCB mix, i.e., that PCB homologue composition was not altered due to weathering. This assumption probably is incorrect. To investigate the significance of this, an error analysis was performed for the correction factors developed for regions of peak overlap. Assuming the worst case, i.e., a $100 \%$ error in the assignment of area to one or the other peak, resulted in an approximate error estimate of only $20 \%$ for total peak area: the actual error was probably much smaller.

Average chlorine numbers were calculated by dividing the sum of the products of homologue concentration times the homologue chlorine number $(1-10)$ by total PCB concentration using the following equation:

$$
\text { Average chlorine number }=\sum_{\mathrm{i}=1}^{10}\left(\mathrm{C}_{\mathrm{i}} * \mathrm{Cl}_{\mathrm{i}}\right) / \sum_{\mathrm{i}=1}^{10} \mathrm{C}_{\mathrm{i}}
$$

where $C_{i}=$ concentration of the homologue with i substituted chlorine atoms

$\mathrm{Cl}_{\mathrm{i}}=$ number of chlorine atoms in the $\mathrm{i}^{\text {th }}$ homologue.

Contaminant concentrations are expressed in terms of $\mu \mathrm{g} / \mathrm{g}$ dry weight. Because sculpins were not freeze-dried, contaminant concentrations were initially calculated in terms of wet weight. These values were converted to dry weight by assuming that sculpins were $80 \%$ water (M. Simmons, University of Michigan, personal communication).

\section{Contaminant Reservoirs and Recycling in M. relicta and $\mathrm{P}$. hoyi}

The relative contribution of $M$. relicta and $P$. hoyi to the offshore contaminant reservoir ( $\mu \mathrm{g}$ contaminant $/ \mathrm{m}^{2}$ ) was calculated by multiplying average contaminant body burden ( $\mu \mathrm{g} / \mathrm{g}$ : this study) by average annual standing stock $\left(\mathrm{g} / \mathrm{m}^{2}\right)$. Estimates of average $P$. hoyi biomass (B) and productivity (P) are based on Lubner's (1979) determinations at a 90 - and $115-\mathrm{m}$ station in Lake Michigan. Estimates of average $M$. relicta biomass and productivity are based on Sell's (1982) determinations at a 74- and 115-m station in Lake Michigan.

Contaminant turnover rate $\left(\mathrm{yr}^{-1}\right)$ also was compared for offshore $P$. hoyi and $M$. relicta populations. Contaminant turnover occurs through two processes. The first is the direct chemical elimination $(\mathrm{K})$ of the compound. The second is through biomass turnover $(\mathrm{P} / \mathrm{B})$ and includes considerations of organism growth and mortality. Over the long-term, where both elimination and growth take place, contaminant elimination rates are the sum of instantaneous growth rate (estimated by $\mathrm{P} / \mathrm{B}$ ) and $\mathrm{K}$ (Pentreath and Jefferies 1971). K provides a lower estimate while the sum of $K$ and $P / B$ provides an upper estimate of contaminant turnover rate.

Estimates of $\mathrm{K}$ are based on laboratory studies conducted by Evans and Landrum (1989). For the purposes of these calculations, it is assumed that their estimates of DDE elimination are representative of that for total DDT: this is reasonable given the fact that DDE is the predominant component of total DDT in $P$. hoy $i$ and $M$. 
relicta. It is also assumed that their estimates of $2,4,5,2^{\prime}, 4^{\prime}, 5^{\prime}$-hexachlorobiphenyl (HB) elimination are representative of that for total PCB, which appears to be a reasonable assumption. Previous studies have shown that the elimination rate of the polynuclear aromatic compounds benzo(a)pyrene, anthracene, and phenanthrene are remarkably similar within both $P$. hoyi $(0.002-0.004 / \mathrm{h})$ and $M$. relicta $(0.012-0.015 / \mathrm{hr})$ : the major differences in elimination rate are associated with species rather than compound (Frez and Landrum 1986). $\mathrm{HB}$ is a significant component of total $\mathrm{PCB}$ in various regions of the Great Lakes (Oliver 1984; Smith et al. 1985). Estimates of $P$. hoyi and $M$. relicta $\mathrm{P} / \mathrm{B}$ are based on Lubner (1979) and Sell (1982) as described above.

Population contaminant turnover rate $\left(\mu \mathrm{g} / \mathrm{m}^{2} / \mathrm{yr}\right)$ incorporates considerations of population areal contaminant concentration $\left(\mu \mathrm{g} / \mathrm{m}^{2}\right)$ and contaminant turnover rate $\left(\mathrm{yr}^{-1}\right)$. The lower estimate is the product of population areal contaminant concentration and $\mathrm{K}$ : the upper estimate is the product of population areal contaminant concentration and the sum of $K$ and $P / B$.

\section{Results}

\section{Contaminant Concentrations}

There was no evidence that organic contaminant concentrations differed substantially between the two plankton meshsize series, the three mysid size-categories, or the five particle-flux depth intervals. Therefore, data from each of these collection series were pooled. Mean contaminant concentrations were calculated for each of the investigated ecosystem components: plankton, $M$. relicta, $P$. hoyi, sculpins, sediment, and particle flux.

Total PCB concentration (Figure 1) varied substantially between the various ecosystem components from a mean low value of $0.09 \mu \mathrm{g} / \mathrm{g}$ in sediments to a mean high value of $4.46 \mu \mathrm{g} / \mathrm{g}$ in sculpins. PCB concentrations in particle flux (mean $=0.45 \mu \mathrm{g} / \mathrm{g}$ ) were considerably higher than in the sediments and approximated that of the plankton (mean = $0.35 \mu \mathrm{g} / \mathrm{g}$ ). Total PCB body burdens were substantially higher in $P$. hoyi (mean $=1.12 \mu \mathrm{g} / \mathrm{g}$ ) than $M$. relicta (mean $=0.49 \mu \mathrm{g} / \mathrm{g}$ ). There was little evidence that PCB was strongly biomagnified from plankton to mysids. In contrast, PCB was strongly biomagnified from macrobenthos (amphipods and mysids) to sculpins and from detritus (sediments, particle flux) to $P$. hoyi (Table 1).

Sediment trap material had an average chlorine number of 3.8 , a value substantially lower than the other ecosystem compartments. Surficial sediments and plankton were composed of more highly chlorinated PCB homologues (average chlorine number $=4.6$ ). The average chlorine number of the PCBs increased from 4.5 in $M$. relicta to 4.7 in $P$. hoyi and 5.0 in sculpins.

Sediment trap material was dominated by the lower chlorinated PCB homologues with $36 \%$ of the PCBs containing two or three chlorine atoms. This percentage decreased to $12-16 \%$ in sediment, plankton, and $M$. relicta, and to $5-6 \%$ in $P$. hoyi and sculpins. Higher chlorinated (five and six chlorine atoms per molecule) PCB homologues accounted for $23 \%$ of the total PCB in particle flux, $54-56 \%$ in plankton, sediments, and $M$. relicta, $61 \%$ in $P$. hoyi, and $74 \%$ in sculpins.

Toxaphene concentrations (Figure 1) ranged from below

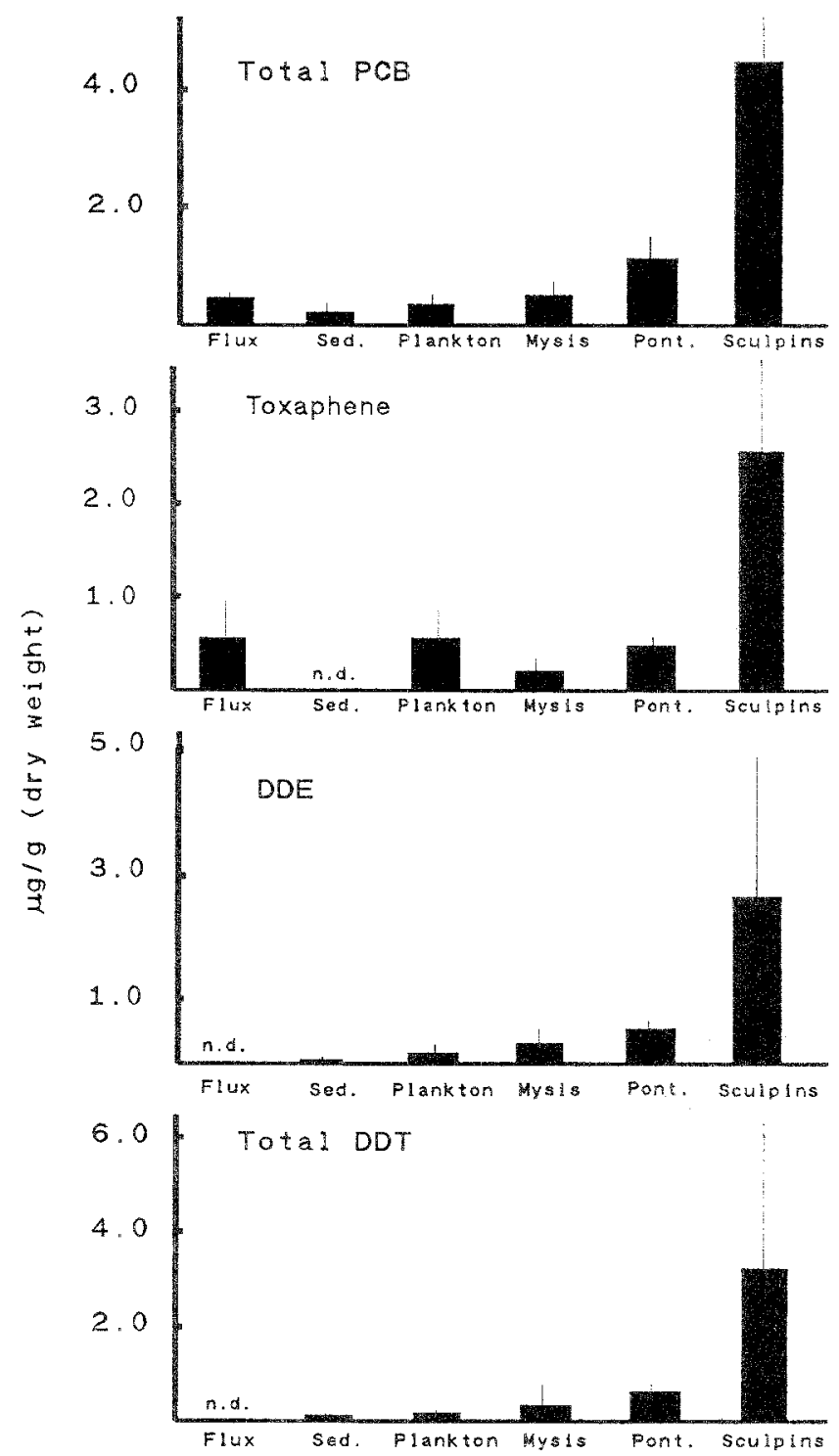

Fig. 1. Mean (plus 1 standard deviation) contaminant concentrations in particle flux, surficial sediments, plankton, Mysis relicta, Pontoporeia hoyi, and deepwater sculpins at an offshore station in Lake Michigan. n.d. = not determined

detection limits for sediments to a mean value of $2.57 \mu \mathrm{g} / \mathrm{g}$ for sculpins. Like PCB, toxaphene concentrations were similar in sediment trap material (mean $=0.55 \mu \mathrm{g} / \mathrm{g}$ ) and in the plankton (mean $=0.55 \mu \mathrm{g} / \mathrm{g}$ ). Toxaphene concentrations (also like PCB) were substantially higher in $P$. hoyi (mean $=$ $0.47 \mu \mathrm{g} / \mathrm{g}$ ) than in $M$. relicta (mean $=0.18 \mu \mathrm{g} / \mathrm{g}$ ). However, in contrast to PCB, toxaphene concentrations did not increase from the plankton to $M$. relicta nor to $P$. hoyi (Table 1). Moreover, $M$. relicta, $P$. hoyi, and sculpins contained approximately half as much toxaphene as PCB.

DDE was the predominant form of DDT in the Lake Michigan ecosystem, accounting for over $75 \%$ of total DDT. Its distribution, while generally similar to that of $P C B$, differed in some aspects (Figure 1). For example, like PCB, DDE concentrations were greater in $P$. hoyi (mean $=0.53$ $\mu \mathrm{g} / \mathrm{g}$ ) than in $M$. relicta (mean $=0.30 \mu \mathrm{g} / \mathrm{g}$ ). Highest concentrations were observed in sculpins (mean $=2.64 \mathrm{\mu g} / \mathrm{g}$ ) 
Table 1. Biomagnification factors for PCB, total DDT, toxaphene, and mercury between successive trophic levels in Lakes Michigan and Ontario food webs. Data for Lake Ontario were calculated from Tables 1 and 2 from Borgmann and Whittle (1983)

\begin{tabular}{|c|c|c|c|c|}
\hline & $\begin{array}{l}\text { Lake } \\
\text { Michigan }\end{array}$ & $\begin{array}{l}\text { Lake Ontario } \\
\text { Western }^{\mathrm{a}}\end{array}$ & Eastern $^{\mathrm{b}}$ & Mean \\
\hline \multicolumn{5}{|l|}{ Polychlorinated biphenyls } \\
\hline Mysids: plankton & 1.3 & 1.3 & 1.5 & 1.4 \\
\hline Amphipods: plankton & 3.2 & 5.4 & 8.5 & 5.7 \\
\hline Fish: plankton & 12.9 & 21.8 & 19.1 & 17.9 \\
\hline Amphipods: mysids & 2.4 & 4.3 & 5.9 & 4.2 \\
\hline Fish: mysids & 9.2 & 17.3 & 13.2 & 13.2 \\
\hline Fish: amphipods & 4.0 & 4.0 & 2.3 & 3.4 \\
\hline Amphipods: sediment & 12.2 & & & 12.2 \\
\hline \multicolumn{5}{|l|}{ Total DDT } \\
\hline Mysids: plankton & 3.0 & 3.5 & 2.0 & 2.8 \\
\hline Amphipods: plankton & 5.4 & 6.0 & 11.5 & 7.6 \\
\hline Fish: plankton & 28.7 & 27.5 & 16.2 & 24.1 \\
\hline Amphipods: mysids & 1.8 & 1.7 & 5.8 & 3.1 \\
\hline Fish: mysids & 9.7 & 7.9 & 8.1 & 8.6 \\
\hline Fish: amphipods & 5.3 & 4.6 & 1.4 & 3.8 \\
\hline Amphipods: sediment & 21.0 & - & - & 21.0 \\
\hline \multicolumn{5}{|l|}{ Toxaphene } \\
\hline Mysids: plankton & 0.4 & - & - & 0.4 \\
\hline Amphipods: plankton & 0.9 & - & - & 0.9 \\
\hline Fish: plankton & 4.7 & - & - & 4.7 \\
\hline Amphipods: mysids & 2.6 & - & - & 2.6 \\
\hline Fish: mysids & 14.3 & - & - & 14.3 \\
\hline Fish: amphipods & 5.5 & - & - & 5.5 \\
\hline \multicolumn{5}{|l|}{ Mercury } \\
\hline Mysids: plankton & - & 3.0 & 1.7 & 2.4 \\
\hline Amphipods: plankton & - & - & 1.8 & 1.8 \\
\hline Fish: plankton & - & 9.0 & 11.8 & 10.4 \\
\hline Amphipods: mysids & - & - & 1.1 & 1.1 \\
\hline Fish: mysids & - & 3.0 & 7.1 & 5.1 \\
\hline Fish: amphipods & - & - & 6.5 & 6.5 \\
\hline
\end{tabular}

a Fish calculations based on smelt

${ }^{b}$ Fish calculations based on slimy sculpins

while lowest concentrations were associated with surficial sediments (mean $=0.03 \mu \mathrm{g} / \mathrm{g}$ ). However, in contrast to PCB (and toxaphene), DDE concentrations were substantially higher in mysids than in the plankton (mean $=0.09 \mu \mathrm{g} / \mathrm{g}$ ). Particle flux samples were not analyzed for DDT and its metabolites.

DDD and DDT concentrations were substantially lower than DDE. Concentrations appeared to follow the same basic distribution as DDE, i.e., greater concentrations in amphipods than mysids and highest concentrations in sculpins. Total DDT concentration patterns (Figure 1) followed that of DDE. Total DDT concentrations averaged 0.03 $\mu \mathrm{g} / \mathrm{g}$ in sediment, $0.11 \mu \mathrm{g} / \mathrm{g}$ in plankton, $0.33 \mu \mathrm{g} / \mathrm{g}$ in $M . r e-$ licta, $0.61 \mu \mathrm{g} / \mathrm{g}$ in $P$. hoyi, and $3.25 \mu \mathrm{g} / \mathrm{g}$ in sculpins.

\section{P. hoyi and M. relicta Areal Contaminant Concentra- tions and Turnover Offshore}

Amphipod biomass averaged $3.2 \mathrm{~g} / \mathrm{m}^{2}$ versus $0.7 \mathrm{~g} / \mathrm{m}^{2}$ for mysids (Table 2). Because of its greater areal biomass and contaminant concentration, the offshore $P$. hoyi contains approximately 12.0 times more $\mathrm{PCB}, 9.5$ times more total DDT, and 15.0 times more toxaphene than the offshore $M$. relicta population.
Table 2. Comparative population dynamics and contaminant concentrations in Pontoporeia hoyi and Mysis relicta in the offshore region of Lake Michigan. See text for additional explanation

\begin{tabular}{llll}
\hline & $\begin{array}{l}P . \\
\text { hoyi }\end{array}$ & $\begin{array}{l}M . \\
\text { relicta }\end{array}$ & Amphipod:mysid \\
\hline (1) Standing stock \& productivity & & \\
Biomass (g/m $\mathrm{m}^{2}$ dry wt.) & 3.2 & 0.7 & 4.6 \\
Production $\left(\mathrm{g} / \mathrm{m}^{2} / \mathrm{yr}\right)$ & 3.6 & 2.1 & 1.7 \\
Production:biomass (yr $\left.{ }^{-1}\right)$ & 1.1 & 3.0 & 0.4 \\
(2) Population areal contaminant concentration & \\
Total DDT ( $\mu \mathrm{g} / \mathrm{m}^{2}$ dry wt.) & 1.9 & 0.2 & 8.4 \\
PCB $\left(\mu \mathrm{g} / \mathrm{m}^{2}\right.$ dry wt.) & 3.6 & 0.3 & 10.5 \\
Toxaphene $\left(\mu \mathrm{g} / \mathrm{m}^{2}\right.$ dry wt.) & 1.5 & 0.1 & 10.7 \\
\hline
\end{tabular}

Lower estimates of contaminant turnover rate $(\mathrm{K})$, based on laboratory studies, suggest that an individual $P$. hoy $i$ is 1.9 times more efficient at eliminating DDE (and presumably total DDT) and 6.2 times more efficient at eliminating $\mathrm{HB}$ (and possibly total PCB) than an individual $M$. relicta: however, $M$. relicta is approximately 2.8 times more efficient than $P$. hoyi at eliminating the polyaromatic hydrocarbon $\mathrm{BaP}$ (Table 3). Upper estimates of contaminant turnover rate (based on the sum of $\mathrm{K}$ and $\mathrm{P} / \mathrm{B}$ ) also suggest that $P$. hoyi turns over DDT and $\mathrm{PCB}$ at a greater rate than $M$. relicta 
Table 3. Comparative contaminant parameters for Pontoporeia hoyi and Mysis relicta in the offshore region of Lake Michigan. elimin. = elimination. contam. = contaminant. See text for additional explanation

\begin{tabular}{|c|c|c|c|}
\hline & $\begin{array}{l}\text { K (elimin.) } \\
\left(\mathrm{yr}^{-1}\right)\end{array}$ & $\begin{array}{l}\text { Contamin. } \\
\text { turnover } \\
\left(\mathrm{yr}^{-1}\right)\end{array}$ & $\begin{array}{l}\text { Population } \\
\text { contam. } \\
\text { turnover } \\
\left(\mu \mathrm{g} / \mathrm{m}^{2} / \mathrm{yr}\right)\end{array}$ \\
\hline \multicolumn{4}{|l|}{ DDT } \\
\hline P. hoyi & 8.6 & $8.6-9.7$ & $16.6-18.8$ \\
\hline M. relicta & 4.5 & $4.5-7.5$ & $1.0-1.6$ \\
\hline \multicolumn{4}{|c|}{ Polychlorinated biphenyl } \\
\hline P. hoyi & 6.8 & $6.8-7.8$ & $24.4-28.4$ \\
\hline$M$. relicta & 1.1 & $1.1-4.1$ & $0.4-1.3$ \\
\hline \multicolumn{4}{|c|}{ Benzo(a)pyrene } \\
\hline$P$. hoyi & 14.7 & $1.1-15.9$ & \\
\hline M. relicta & 41.2 & $3.1-44.2$ & \\
\hline
\end{tabular}

a From experimental studies of Evans and Landrum (1989). Contaminant half-life and elimination rate for DDT and PCB based on DDE and the PCB congener $2,4,5,2^{\prime}, 4^{\prime}, 5^{\prime}$-hexachlorobiphenyl, respectively

while $M$. relicta turns over $\mathrm{BaP}$ at a higher rate than $P$. hoyi (Table 3).

Population contaminant turnover rates incorporate considerations of population areal contaminant concentration (Table 2) and the upper and lower estimates of contaminant turnover rate (Table 3 ). Based on the results of these calculations, the offshore $P$. hoyi population recycles approximately 12-17 times more total DDT and 22-61 times as much PCB as the offshore $M$. relicta population.

\section{Discussion}

\section{Food Chain Biomagnification}

The distributions of PCB, toxaphene, and DDE in the Lake Michigan ecosystem were similar in some respects and markedly different in others. All three classes of compounds exhibited a pronounced trend of trophic biomagnification (Table 1). DDE was the most strongly biomagnified compound increasing 28.7-fold in concentration from plankton to sculpins: PCB concentration increased 12.9-fold from plankton to sculpins while toxaphene concentration increased only 4.7 -fold from plankton to sculpins. Although there were large differences between PCB, DDT, and toxaphene biomagnification from plankton to fish, differences were considerably smaller for mysid:amphipod:sculpin comparisons than for mysid:plankton and amphipod:plankton comparisons. Similarly, Oliver and Niimi (1988) observed a much greater differential partitioning of PCB congeners at the lower end of the food chain (water to plankton to mysids) than at the higher end (mysids to smelt to salmonids).

Relative differences in contaminant concentration between trophic levels are similar in Lake Michigan (this study) and Lake Ontario (Table 1; Borgmann and Whittle 1983). Moreover, the southeastern Lake Michigan data verify the general relationship between animal size and con- taminant (PCB, DDT) body burden as established by Borgmann and Whittle (1983). These observations suggest that approximate estimates of contaminant (PCB, DDT) concentration in higher trophic levels may be obtained from determinations of contaminant concentrations in lower trophic levels, i.e., through the application of the appropriate biomagnification factor (BMF). For example, a BMF of 3.4 would be applied to estimate PCB concentrations in forage fish based on $P$. hoyi PCB determinations.

\section{Polychlorinated Biphenyl Homologue Composition}

Depuration of organic contaminants such as PCB from organisms often involves the selective loss of the lower chlorinated compounds (Brown et al. 1987), resulting in a proportionate increase in the more highly chlorinated compounds within the organism. Thus, biomagnification and chlorinenumber composition may be interrelated as our data suggest. Sculpins and $P$. hoyi, which contained the highest concentrations of $\mathrm{PCB}$, also contained a greater percentage ( $74 \%$ and $61 \%$, respectively) of the higher chlorinated ( 5 and 6 chlorine atoms per molecule) PCB homologues than plankton and $M$. relicta (54\% and $56 \%$, respectively). The greater proportion of more highly-chlorinated PCB homologues in $P$. hoyi and sculpins does not appear to be directly related to the benthic habitat of these organisms. Sediments had an average chlorine number of 4.6 , a value similar to that for plankton and mysids. Other researchers also have observed that total PCB concentration and chlorine content increases with increasing trophic level (Oliver and Nimi 1988).

Although PCB concentrations in plankton and particle flux were similar, there were marked differences in average PCB chlorine number. Particle flux was strongly dominated by the lower chlorinated PCB molecules, with an average chlorine number of $3.8 \mathrm{vs} 4.6$ in the plankton. Relatively low PCB average chlorine numbers may be associated with the two major sources of these PCB molecules, i.e., zooplankton egestion products and atmospheric inputs.

Zooplankton fecal pellets may contain relatively high concentrations of PCB (Elder and Fowler 1977; Evans et al. 1982). Moreover, egestion may involve the selective loss of the lower-chlorinated PCB homologues with the egested matter. For example, while $M$. relicta contains greater amounts of the Aroclor 1254 than the less chlorinated Aroclor $1242^{8}$, its fecal pellets contain proportionately more Aroclor $1242^{\circledR}$ than $1254^{\circledR}$ (Evans et al. 1982). Zooplankton egestion products dominate particle flux (on a dry weight basis) during much of the year (Evans, unpublished data). Zooplankton, by egesting proportionately high concentrations of the lower chlorinated PCB homologues, may be an important factor affecting particle-flux PCB composition.

Another important factor affecting the PCB composition of particle flux is atmospheric sources of PCB. Aroclor $1242^{\circledR}$ predominates over Aroclor $1254^{(1)}$ in air but is underrepresented relative to aroclor $1254^{\circ}$ in lake water (Rice et al. 1982); this suggests that atmospheric inputs are relatively enriched in the lower-chlorinated PCB congeners. Because PCB is relatively insoluble in water, it may be rapidly adsorbed onto the organic matter comprising particle flux. Thus, atmospheric sources of PCB may also account for the 
fact that particle flux is dominated by the lower chlorinated PCB molecules.

\section{Differences in $\mathrm{P}$. hoyi and $\mathrm{M}$. relicta Contaminant Body Burdens}

In comparison to $M$. relicta, $P$. hoyi contains relatively high concentrations of total DDE and PCB. This observation is unexpected, given the results of other studies. Body size and contaminant (PCB, total DDT, mercury) body burden are linearly related for Lake Ontario biota (Borgmann and Whittle 1983), suggesting that contaminant concentrations should be slightly lower in $P$. hoyi than the larger $M$. relicta. Moreover, $M$. relicta is more effective than $P$. hoy $i$ at bioconcentrating DDE and HB from water (Evans and Landrum 1989), suggesting that field populations of $P$. hoyi would contain lower DDE and PCB concentrations than $M$. relicta: the converse was observed. Discrepancies between predicted and measured relative differences in DDE and PCB concentrations in $P$. hoyi and $M$. relicta could be due to several factors.

Although $P$. hoyi and $M$. relicta were collected from the same region (sediment-water interface) of the offshore zone of Lake Michigan, these two species exhibit significant differences in their ecology. Mysis relicta is predominantly an epibenthic species, inhabiting the sediment-water interface during the daylight hours and migrating to the surface at night (Mozley and Howmiller 1977). This vertical migration into warmer waters may result in an thermally-induced increase in contaminant elimination rates. In contrast, $P$. hoyi is a benthic species, found primarily in the upper few centimeters of the sediments (Mozley and Howmiller 1977). Thus, $P$. hoyi is exposed to relatively low and constant temperatures $\left(<9^{\circ} \mathrm{C}\right)$ in the offshore region: its average daily contaminant elimination rate may also remain low. Moreover, by burrowing in the sediments, $P$. hoyi may be exposed to higher concentrations of dissolved organic contaminants in the pore water than the epibenthic $M$. relicta is exposed to in the water column.

Differences in feeding characteristics may also be an important factor affecting differences in mysid and amphipod contaminant body burdens. Early $M$. relicta instars are herbivorous while later instars are omnivorous: $P$. hoy $i$ is primarily a detritivore ingesting sediments, associated organic matter, and bacteria (Mozley and Howmiller 1977). As a consequence of dietary differences, amphipods may ingest greater amounts of material and associated organic contaminants (such as DDE and PCB) than mysids.

Amphipods, as detritivores, feed intermittently during some seasons (Quigley 1988): interrupted feeding may result in decreased egestion rates and increased contaminant bioaccumulation rates (Leversee et al. 1982). Decreased feeding results in a decrease in defecation and a possible increase in contaminant assimilation rate (Klump et al. 1987). In contrast, $M$. relicta, as a vertical migrator, is exposed to a more constant food supply and thus is less likely to exhibit seasonally-interrupted feeding with a concomitant increase in contaminant assimilation rate.

\section{Role of $\mathrm{P}$. hoyi and $\mathrm{M}$. relicta in Recycling} of Contaminants

The relative roles of $P$. hoy $i$ and $M$. relicta in the offshore storage and recycling of PCB, DDT, and toxaphene are substantially different and are due to three factors: the relative differences in $P$. hoyi and $M$. relicta standing stocks, contaminant body burdens, and contaminant turnover rates. In the offshore region, $P$. hoyi occur in approximately 4.6 times greater standing stocks than $M$. relicta: in addition, $P$. hoyi have higher total PCB, DDT, and toxaphene body burdens than $M$. relicta. Thus, $P$. hoyi represents a greater (by a factor of 10-12) reservoir than $M$. relicta for these organic contaminants in the offshore region of Lake Michigan. These results are significant given the fact that, as a major food item for a variety of Great Lakes fish, $P$. hoy $i$ is important in the food web biomagnification of organic contaminants from sedimentary sinks to benthic- and pelagic-feeding fish (Jensen et al. 1982; Breck and Bartell 1988).

In the laboratory, $P$. hoy $i$ is more efficient than $M$. relicta at eliminating DDE (and presumably total DDT) and HB (and possibly total PCB). This is especially significant, since $P$. hoy $i$ also has a higher $\mathrm{P} / \mathrm{B}$ and areal contaminant concentration than $M$. relicta. Thus, offshore populations of $P$. hoyi may recycle 12-17 times more total DDT and 22-61 times more PCB than the offshore $M$. relicta population.

Finally, the relative importance of $P$. hoy $i$ in contaminant recycling in the Lake Michigan ecosystem can be evaluated in the context of total DDT precipitation inputs. The annual precipitation loading of DDT residues to Lake Michigan has been estimated at $2.4 \mu \mathrm{g} / \mathrm{m}^{2} / \mathrm{yr}$ (Murphy 1984), a value some 7-8 times lower than the estimated DDT turnover rate $\left(16.6-18.8 \mu \mathrm{g} / \mathrm{m}^{2} / \mathrm{yr}\right.$ ) by offshore $P$. hoyi. PCB atmospheric loadings have been estimated at $86.2 \mu \mathrm{g} / \mathrm{m}^{2} / \mathrm{yr}$ (assuming a total deposition of $5,000 \mathrm{~kg} / \mathrm{yr}$ over the $58,000 \mathrm{~km}^{2}$ surface area of Lake Michigan; Murphy and Rzeszutko 1977). Assuming that $P$. hoyi recycles total PCB at the same rate as estimated for $\mathrm{HB}$, the offshore population may recycle the equivalent of $28-33 \%$ of the precipitation of PCB falling directly into offshore Lake Michigan.

In summary, the results of this study suggest that $P$. hoyi is an important macroinvertebrate species in the storage and recycling of total DDT, $\mathrm{PCB}$, and toxaphene in offshore Lake Michigan and support the suggestion that $P$. hoyi could serve as a useful biological indicator of Great Lakes ecosystem quality (Ryder and Edwards 1985).

Acknowledgments. This research was supported by project numbers R/TS-14 and R/ER-16 under grant number NA80AA-D00072 and project number R/-26 under grant number NA85AA-DSG045C from the Office of Sea Grant, National Oceanographic and Atmospheric Administration, U.S. Department of Commerce, and funds from the State of Michigan. Partial support also was provided by the Office of Research and Development, U.S. Environmental Protection Agency through Grant number R-812311-0109. The Great Lakes Environmental Research Laboratory, NOAA provided ship time in 1982. Dr. Brian Eadie, GLERL, provided the use of sediment traps. Ted Ladewski, CGLAS, wrote the computer programs to calculate the average number of chlorine atoms per PCB homologue. Dr. Uwe Borgmann, Canada Centre for Inland Waters, 
and Dr. Peter Landrum, GLERL, provided helpful comments in the scientific review of this manuscript. Contribution No. 523 of the Center for Great Lakes and Aquatic Sciences.

\section{References}

Borgmann U, Whittle DM (1983) Particle-size-conversion efficiency and contaminant concentrations in Lake Ontario biota. Can $\mathbf{J}$ Fish Aquat Sci 40:328-336

Breck JE, Bartell SM (1988) Approaches to modelling the fate and effects of toxicants in pelagic systems. In: Evans MS (ed) Toxic contaminants and ecosystem health: A Great Lakes Focus. Wiley, New York, pp 427-446

Brown JR JF, Wagner RE, Feng H, Bedard DL, Brennan MJ, Carnahan JC, May RJ (1987) Environmental dechlorination of PCBs. Environ Contam Toxicol 6:579-594

Elder DL, Fowler SW (1977) Polychlorinated biphenyls: Penetration into the deep ocean by zooplankton fecal pellet transport. Science 197:459-460

Evans MS, Bathelt RW, Rice CP (1982) PCBs and other toxicants in Mysis relicta. Hydrobiologia 93:205-215

Evans MS, Landrum PF (1989) Toxicokinetics of DDE, benzo(a)pyrene, and $2,4,5,2^{\prime}, 4^{\prime}, 5^{\prime}$-hexachlorobiphenyl in Pontoporeia hoyi and Mysis relicta. J Great Lakes Res 15:589-600

Frez, WA, Landrum PF (1986) Species-dependent uptake of PAH in Great Lakes invertebrates. In: Cooke MW, Dennis JA (eds). Polynuclear Aromatic Hydrocarbons. Ninth International Symposium on Chemistry, Characterization, and Carcinogenesis. Batelle Press, Columbus, OH, pp 291-304

Hallett DJ (1988) Ecosystem management of persistent toxic chemicals-back to basics. In: Evans MS (ed) Toxic contaminants and ecosystem health: A Great Lakes Focus. Wiley, New York, pp 491-512

Jensen AL, Spigarelli SA, Thommes MM. (1982). PCB uptake by five species of fish in Lake Michigan, Green Bay of Lake Michigan, and Cayuga Lake, New York. Can J Fish Aquat Sci 39:700-709

Klump JV, Krezoski JR, Smith ME, Kaster JL (1987) Dual tracer studies of the assimilation of an organic contaminant from sediments by deposit feeding oligochaetes. Can J Fish Aquat Sci $44: 1574-1583$

Leversee GJ, Giesy JP, Landrum PF, Gerould S, Bowling JW, Fannin TE, Haddock JD, Bartell SM (1982) Kinetics and biotransformation of benzo(a)pyrene in Chironomus riparius. Arch Environ Contam Toxicol 11:25-31

Lubner JF (1979) Population dynamics and production of the relict amphipod Pontoporeia hoyi, at several Lake Michigan stations. PhD Thesis, University of Wisconsin-Milwaukee, Milwaukee, WI
Mozley SC, Howmiller RP (1977) Environmental status of the Lake Michigan region. Vol. 6: Zoobenthos of Lake Michigan. Argonne National Laboratory, Argonne, IL

Murphy TJ, Rzeszutko CP (1977) Precipitation inputs of PCBs to Lake Michigan. J Great Lakes Res 3:305-312

Murphy TJ (1984) Atmospheric inputs of chlorinated hydrocarbons to the Great Lakes. In: Nriagu JO, Simmons MS (eds) Toxic contaminants in the Great Lakes. Wiley, New York, pp 53-80

Oliver BG (1984) Uptake of chlorinated organics from anthropogenically contaminated sediments by oligochaete worms. Can J Fish Aquat Sci 41:878-883

Oliver BG, Nimi AJ (1988) Trophodynamic analysis of polychlorinated biphenyl congeners and other chlorinated hydrocarbons in the Lake Ontario ecosystem. Environ Sci Technol 22:388397

Pentreath RJ, Jefferies DF (1971) The uptake of radionuclides by 1-group plaice (Pleuronectes platessa) off the Cumberland coast, Irish Sea. I mar biol Assoc UK 51:963-976

Quigley MA (1988) Gut fullness of the deposit-feeding amphipod, Pontoporeia hoyi, in southeastern Lake Michigan. J Great Lakes Res 14:178-187

Rice CP, Eadie BJ, Erstfield KM (1982) Enrichment of PCBs in Lake Michigan surface films. J Great Lakes Res 8:265-270

Rice CP, White DS (1987) PCB availability assessment of river dredging using caged clams and fish. Environ Toxicol Chem 6:259-274

Ryder RA, Edwards (1985) A Conceptual Approach for the Application of Biological Indicators of Ecosystem Quality in the Great Lakes Basin. Report to the Great Lakes Science Advisory Board, International Joint Commission, Windsor, Canada, $169 \mathrm{pp}$

Sawyer LD (1978) Quantification of polychlorinated biphenyl residues by electron capture gas-liquid-chromatography: Reference material characterization and preliminary study. I Assoc Offic Anal Chem 61:272-281

Sell DW (1982) Size-frequency estimates of secondary production by Mysis relicta in Lakes Michigan and Huron. Hydrobiologia 93:69-78

Smith VE, Spurr JM, Filkins JC, Jones JJ (1985) Organochlorine contaminants in herring gull eggs from the Detroit and Niagara rivers and Saginaw bay (1978-1982): Contaminant discriminants. J Great Lakes Res 11:223-230

Webb RG, McCall AC (1973) Quantitative PCB standards for electron capture gas chromatography. J Chromatogr Sci 11:366-372

Manuscript received March 24, 1989 and in revised form December 30, 1989. 